Menachem Rosner and Arnold S. Tannenbaum

\title{
Organizational efficiency and egalitarian democracy in an intentional communal society: the kibbutz ${ }^{1}$
}

\begin{abstract}
Kibbutzim differ from one another in democratic and egalitarian practice and in equality itself. We explore hypotheses in 49 kibbutzim that attempt to explain these differences by the opposing effects of a technological imperative that implies a rational striving for economic efficiency and an ideological imperative that implies a commitment by members to traditional kibbutz values. Cross sectional data were obtained from economic records of the kibbutz federations and from four survey research studies in kibbutzim. They suggest, with some significant exceptions, opposing effects of the two imperatives on democratic and egalitarian practices although not necessarily of one imperative on the other. Implications are discussed for theories about the inconsistency between technological progress and communality.
\end{abstract}

This research explores hypotheses regarding the conflict between the striving for organizational efficiency and the values of equality and direct democracy in the kibbutz. The kibbutz was conceived as an egalitarian society based on the principle, from each according to his abilities, to each according to his needs. Ultimate decision making power in the governance of the kibbutz resides formally with an assembly that meets weekly and all members can participate in the decisions of this assembly. Thus, the kibbutz, in principle, is an unusually egalitarian and democratic society, although whether it is as egalitarian and democratic as its ideology and formal procedures of governance imply has been a subject of controversy. Change in the kibbutz since its early years from a simple agrarian settlement to a modern, industrialized society implies increased emphasis on a 'technological rationality' that a number of authors argue is inconsistent with the traditional, egalitarian ideology of the kibbutz.

Kibbutzim, in fact, differ from one another in the extent to which they meet their traditional ideals. We explore hypotheses that attempt 
to explain these differences by the opposing effects of a technological imperative on the one hand that implies a rational striving for economic efficiency, and an ideological imperative on the other hand that implies a commitment by members to traditional kibbutz values.

\section{RATIONALE}

The first kibbutzim were established about 75 years ago. They were small agrarian communities in which members were committed to the ideal of settling the land and to the values of equality and direct democracy. There were to be no differences among members in authority, status, or other social and economic rewards. Members received no wages and each member, regardless of his or her work assignment or his or her performance in that assignment, had equal access to the limited goods and facilities available in the kibbutz. Meals were eaten communally and children were raised communally. Officers were elected for short terms and officer positions were rotated among members. Basic decisions were made through meetings in which all members participated. Thus, the traditional kibbutz manifested features of the utopian communal society (Buber 1958; Manuel and Manuel 1979; Erasmus 1977; Blasi 1978; Kanter 1979).

Kibbutzim, however, have since grown in size, numbers and complexity; the kibbutz today is very much a 'modern society' as defined by Inkeles and Smith (1974), with technically advanced farms and factories operated by a skilled work force. Kibbutzim, with about 3 per cent of the Israeli population, produce about 40 per cent of the gross national farm output of Israel and about 5 per cent of the national industrial product. Although they are part of the larger Israeli society, kibbutzim have norms and rules that distinguish them sharply from the larger society. The capacity of kibbutzim to function as societies in their own right, distinct from Israeli society is enhanced by the joining of kibbutzim into four federations through which they provide mutual technical, economic, social, and political support. ${ }^{2}$ Thus, while they are not large - kibbutzim range in size from 50 to 2000 inhabitants including children, with an average of $550-$ kibbutzim have many attributes of a society. We therefore refer to them as communal societies.

As a society, the kibbutz is very much a part of the contemporary world to which it must adapt if it is to survive. A major adaptation has been industrialization and almost every kibbutz now includes at least one industrial factory in addition to its agricultural work branches. Industrialization, however, poses an ideological problem for the kibbutz since the factory, with its hierarchy of authority and emphasis on technological efficiency, appears to contradict traditional values of the kibbutz including equality and direct democracy. 
Blasi (1978) argues that all communities face a 'basic GemeinschaftGesellschaft value dilemma' (Blasi 1978: 3) and Kanter (1972) sees an expression of this dilemma in the general criticism of all utopian societies "that social life cannot be both "human" and "efficient", (Kanter 1972, 148). This criticism derives partly from the objection by critics to utopistic assumptions about 'human nature.' The workability of utopian societies is premised on the assumption of human perfectability or, as in the case of religious utopian sects, on the elimination of evil (Wilson 1973: 25), and on the assumption of 'harmony, cooperation and mutuality of interests . . . (as) natural to human existence ... rather than conflict, competition and exploitation ...' (Kanter 1972:1). In support of these assumptions, Tonnies' (1955) theory of Gemeinschaft, 'starts from the assumption of perfect unity of human wills as an original or natural condition ...' (Tonnies 1955: 42), and authors as diverse as Marx, Cooley, and Skinner argue for the proposition that 'human perfectability' (to use Kanter's term) can be achieved, given the right social conditions. Egoism, which prevails under conditions of capitalist social relations, for example, will, according to Marx (1934) be replaced by a sense of social responsibility under socialist social relations. Full self-realization, according to Cooley (1962), is achieved through social collaboration, identification with the whole and acceptance of 'the higher call of the congenial group' (Cooley 1962:38). Authoritarian need for power does not exist in these circumstances. And for Skinner $(1948,1971)$ persons can learn through positive (non-coercive) reinforcement to be cooperative and altruistic and they will then feel free and fulfilled when they behave cooperatively and altruistically.

Authors of the Human Relations tradition of organizational analysis such as Mayo (1945), McGregor (1960), and Likert (1961), although by no means utopists, share with utopian authors the assumption of harmony, cooperation, and mutuality of interest as natural to human existence. These authors consequently argue for an organizational design that is more personal and communitarian (and more like Tonnies' Gemeinschaft) than is the typical industrial bureaucracy. They see no dilemma in trying to create an organization that is both 'human' and efficient. They therefore see no conflict between the technological imperative and a humanistic, ideological imperative. Weber, however, was clear in asserting an inconsistency between a rational and a more humanistic, associational organization of work. 'Communistic systems for the communal or associational organization of work are unfavorable to calculation and to the consideration of means for obtaining optimum production, because ... they tended to be based on the direct feeling of mutual solidarity' (Weber 1947:205).

Analyses of the kibbutz in the social science literature typically assume the insoluble conflict between being 'human' and being 
efficient or, as did Weber, between the associational and rational organization of work. Cohen (1966), for example, notes a conflict in the Kibbutz between "the tendency towards constant technological, economic and social "progress," and the tenet of "communality" ...' (Cohen 1966:4). Vallier (1962) sees a contradiction in the kibbutz between principles of democracy and egalitarianism on the one hand and 'production imperatives' that lead to specialization, discipline and universalism on the othe hand. Schoeck (1971) argues that in the long run the kibbutz can not meet the rational requirement that technically competent persons serve as leaders since the kibbutz does not provide sufficient material advantages to attract and retain such persons. Nor, according to Dahrendorf (1970) is the ideological prescription in the kibbutz that managers be rotated, likely to be effective in achieving equality since such prescription conflicts with the rational requirement for stability and efficiency.

Direct democracy, according to Rousseau (1950) is possible only in a small agrarian community with a simple, relatively undifferentiated social and economic structure. Such conditions applied well to the early kibbutz, but they do not apply so well today. Kibbutzim have aged, grown and become more differentiated in their occupational and economic structures with the introduction of the factory and its hierarchical authority structure and need for persons with specialized technical skills. Furthermore, some kibbutzim now employ workers who are not members. This practice, which illustrates the effect of the technological imperative, is a rational, economically efficient way of making use of the factory's capital investment in plant and equipment that would otherwise remain partly idle given the small size of the kibbutz work force.

The implacability of the rational, Weberian tendency in the kibbutz is summed up by Rayman.

Its technology, scientific knowledge, marketing skills and organizational format came from the outside. The imposed structures were alien to the original kibbutz ideology. In sociological terms 'Gesellschaft norms pushed against those of Gemeinschaft,' the profane against the sacred, alienation against integration ... A new managerial class of members has been created. The Weberian image of a world dominated by obedient professional managers and bureaucrats, which had been so far from the early kibbutz ideology of practice, has come much closer to being rooted in kibbutz organization (Rayman 1981:264-265; see also Kressel, 1974).

Some students of the kibbutz have taken issue with the assertion that the kibbutz has abandoned its original communal ideals (e.g., Talmon-Garber 1972; Katz and Golomb 1974, 1975). The above general arguments as they apply to the kibbutz are, therefore, controversial. We shall explore in the kibbutz the following hypotheses 
consistent with Weber's assumption of conflict between technological efficiency and solidarity.

1. The ideological and technological imperatives are related negatively to one another; kibbutzim that are high on one are low on the other.

2. The technological imperative has a negative effect and the ideological imperative has a positive effect on democratic and egalitarian practices including: a) participation by members in weekly meetings of the general assembly; b) rotation of kibbutz officers; and c) restraint by the kibbutz in the hiring of outside workers.

3. The above democratic and egalitarian practices have a negative effect on inequality of influence and of material and non-material rewards among members.

4. In part directly and in part indirectly through their effects on democratic and egalitarian practices, the technological imperative has a positive effect and the ideological imperative has a negative effect on inequality of influence and of material and non-material rewards among members.

Our data are cross sectional and we cannot therefore demonstrate causal relations. We can, none the less, explore the relationships suggested by hypotheses 2-4 through the following path diagram.

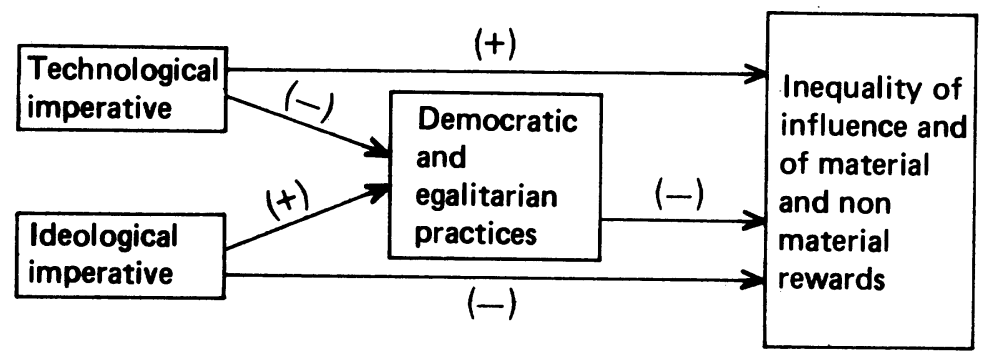

FIGURE I: Path diagram - predictors of inequality in the kibbutz

\section{METHOD}

Our units of analysis are 49 kibbutzim. The measures come from: (a) data about each kibbutz supplied by the statistical and economic departments of the kibbutz federations, the Kibbutz Auditors Association, and the Kibbutz Industry Association, and (b) scores averaged by kibbutz on questions administered through questionnaires to samples of members as part of four earlier studies in which questions pertinent to the present analysis were asked. Because the present analysis includes secondary analyses of data from the above four studies, each of which had its own objective, all of the data from these studies will be standardized by study to minimize the effect of 
differences in method between them. We assume that the withinstudy covariation among variables relevant to the present analysis does not differ among the studies.

These studies are

1. Rosner, Gluck and Avnat (1983) conducted in 1978 in 20 kibbutzim belonging to the four kibbutz federations. Questionnaires were administered to a representative sample of 40 members in each kibbutz.

2. Rosner and Cohen, (1983) conducted in 1976 in 14 kibbutzim of Artzi, the largest federation. Questionnaires were administered to a representative sample of 40 members in each kibbutz.

3. Leviatan, Orchan and Avnat (1977) conducted in 1976 in 9 kibbutzim of Artzi. In each kibbutz, questionnaires were administered to a representative sample of 33 kibbutz-born members who were between 22 and 30 years of age.

4. Leviatan, Amad and Adar (1982), conducted in 1979 in 10 kibbutzim. Questionnaires were administered to a representative sample of 52 members (on the average) over 45 years of age in each kibbutz.

Since some kibbutzim were included in more than one study, the number of kibbutzim in the final sample is 49 rather than the sum of the kibbutzim in each study. In cases of overlap we included the kibbutzim with the more representative sample.

Table I shows the distribution of kibbutzim by study and federation.

TABLE I: Number of kibbutzim by earlier study and federation

\begin{tabular}{lllllr}
\hline & & \multicolumn{3}{c}{ Study } \\
Federation: & 1 & 2 & 3 & 4 & all \\
\hline Artzi & 6 & 14 & 7 & 2 & 29 \\
Meuchad & 6 & - & - & 3 & 9 \\
Ichud & 6 & - & - & 3 & 9 \\
Dati & 2 & - & - & - & 2 \\
All & 20 & 14 & 7 & 8 & 49 \\
\hline
\end{tabular}

\section{MEASURES}

Several indices were constructed, first by intercorrelating individual items that we judged, a priori, to fit the definition in each of the concepts to be measured and then by averaging the items that intercorrelated well.

A. The technological imperative. Intercorrelations among the following 
items were examined in constructing an index of the technological imperative.

1. Economic efficiency. We assume that the striving for productive efficiency that helps to define the technological imperative will be reflected in the economic efficiency of a kibbutz. Shashua and Goldschmidt (1974) describe the rationale for an index of the economic efficiency of a kibbutz and, using this index, they have calculated the efficiency of each kibbutz. Their scores were available through the annual financial balance of the Kibbutz Auditors Association. We have taken the average of the index for each kibbutz during the years 1974-1977. We present Shashua and Goldschmidt's formula in Appendix A.

2. Percentage of total kibbutz income derived from industry. This measure of industrialization, as a component of the technological imperative, was available for each kibbutz from the records of the Kibbutz Industry Association for the year 1976.

3. Percentage of total kibbutz person-days spent in industry. This measure, like the previous one, is taken for the year, 1976 from the records of the Kibbutz Industry Association.

4. Age of industry. We assume that the technological imperative and its effects become more manifest through time as industry becomes established as a normal aspect of kibbutz life. Age of industry was measured by the age of the factory in the kibbutz. Some kibbutzim have more than one factory, in which case the age of the older or oldest factory was used. This information was obtained from the Association of Kibbutz Industries.

5. Age of the kibbutz. We assume that the technological imperative becomes more manifest in an idealistic communal society like the kibbutz as the society ages. Information about age was obtained for each kibbutz from the statistical department of the federation.

6. Size of kibbutz. We assume that size of kibbutz is associated with economic efficiency because of economies of scale both with respect to the consumption and production functions of the kibbutz. Size of kibbutz, available from the statistical department of the kibbutz, is defined as the number of members plus residents who are going through a period of candidacy for membership.

7. Education. The technologically efficient society requires professionals and other highly skilled persons along with an educated work force. Data in the literature document a correlation between education level of the work force and level of industrial development (Russett, et al. 1964; UNESCO 1950). Information about years of formal education (including technical training) of members was obtained as an average score from the questionnaires administered to members within each kibbutz. 
Table II presents the correlations among the above items. Each relates reasonably well to the others with the exception of education. We have therefore constructed an index of the technological imperative by averaging the standardized scores of these items excluding education. (alpha $=.87$ ) The table also shows the correlation of each item with the index. We shall retain education in our analysis as a separate item because of its association with industrialization as it is ordinarily conceptualized even though education does not relate to other aspects of the technological imperative in kibbutzim.

B. The ideological imperative. Hewitt (1977) presents data indicating how political parties with a formal commitment to egalitarian ideology may affect equality in an industrial society. Party ideology can affect the distribution of income, goods, and services through its effect on government policy and legislative action regarding taxation and welfare programs. Thus, economic equality in industrial societies is greater, according to Hewitt's data, where democratic socialist parties are relatively strong. These parties imply the operation of an egalitarian ideological imperative.

The kibbutz federations, like political parties, differ in ideological orientation and in their avowed commitment to traditional kibbutz values. We therefore use the federation affiliation of the kibbutz as the criterion of its ideological commitment and as a measure of the ideological imperative.

The federation, Artzi is the most left leaning of the federations and it distinguishes itself from the others in its commitment to traditional kibbutz values. A survey of member attitudes, for example, showed that members of Artzi, more than members of the other federations, endorsed the principle, 'to each according to his needs,' and came out on the side of democratic ideals when faced with a hypothetical choice between democracy and efficiency (Rosner, Ben David, Avnat, Cohen, and Leviatan 1978). A number of policies and practices that differentiate the federations also provide evidence of the relative strength of an egalitarian ideological imperative in kibbutzim of the Artzi federation. We mention two. Collective child rearing is one manifestation of egalitarian ideological orthodoxy. Traditionally, kibbutz children have been raised collectively, sleeping in 'children's houses' apart from their parents. This egalitarian, collective upbringing is intended as a way of avoiding social stratification. Whatever differences in power or privilege may exist among parents, the effects of such differences on children should be eliminated (or minimized) by a shared and egalitarian socialization. As a result of a growing emphasis on family, however, the federations Ichud in 1966 and Meuchad in 1972, legitimated the practice of children sleeping in their parent's cottage although these federations have maintained their commitment to other aspects of collective child rearing (Shepher and 


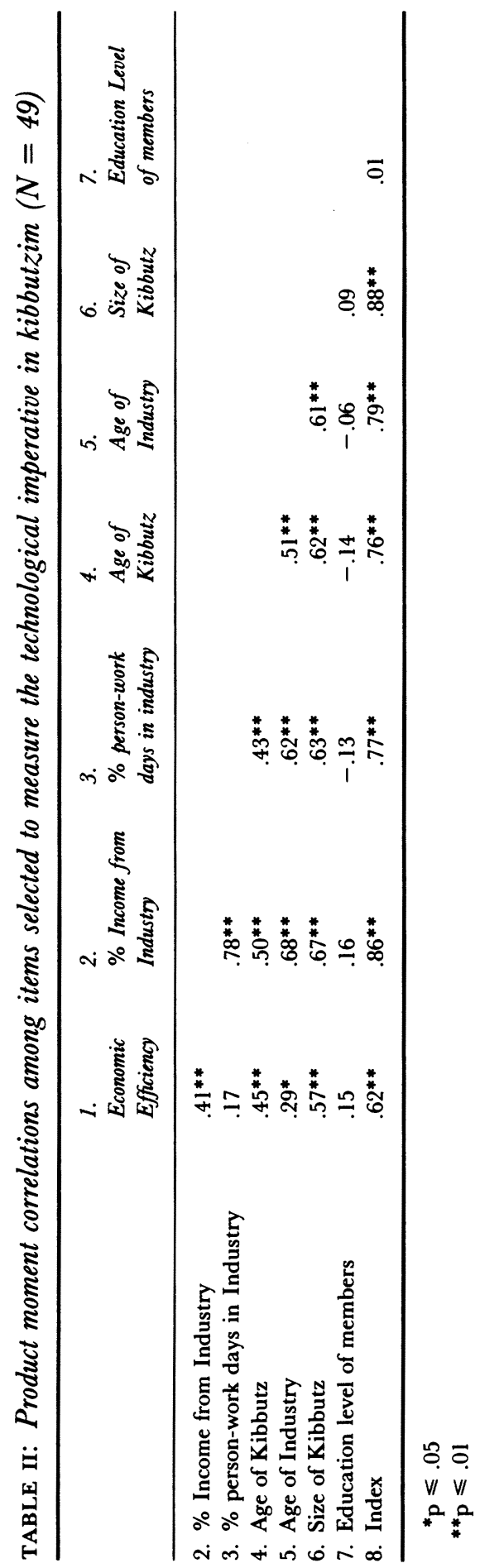


Tiger 1975). By way of contrast, large majorities of the delegates to the 1980 and 1984 conventions of the Artzi Federation voted to maintain children's houses.

A second illustration of ideological orthodoxy in the Artzi Federation can be seen in the rejection by Artzi of formal tests to evaluate individuals in schools and in work. Schools in the Artzi Federation, unlike those in the other federations administer virtually no examinations and they do not issue grades (Rabin and Hazan 1973). We have therefore assigned a score of 2 to kibbutzim in the Artzi federation and a score of 1 to kibbutzim in the other federations as a measure of the ideological imperative. Because, however, two of the four studies in our analysis come exclusively from the Artzi federation we have no variance on the ideological imperative within these two studies. This constancy is likely to have an attenuating affect in the total data set on correlations that may exist between the ideological imperative and other variables and it is likely therefore to result in a conservative test of our hypotheses regarding the ideological imperative.

Although the Artzi Federation differs (in degree) from the others in commitment to traditional ideology, kibbutzim in Artzi are very much like those in the three other federations in important respects. They do not differ significantly in religious commitment, age, size or indices of economic wealth.

C. Democratic and egalitarian practices. Our second hypothesis proposes that the technological imperative has a negative effect and the ideological imperative has a positive effect on democratic and egalitarian practices in the kibbutz. A first such practice is participation by members in the weekly meetings of the kibbutz general assembly, the main decision making body of the kibbutz. Respondents were asked through questionnaires, 'How many of the last 8 meetings of the general assembly have you taken part in?' Answers were coded from 0 to 8 for each respondent and averaged for each kibbutz. The average member of the average kibbutz of this research attended 4.0 meetings, the range for the average member in each kibbutz extending from 2.0 to 5.6 among the 49 kibbutzim.

A second democratic and egalitarian practice is the rotation of offices among members. Each respondent was asked, 'What was the highest office that you held during the last 5 years?' Respondents checked one of the following:

1. I did not hold any office.

2. I was a member of a committee.

3. I was the coordinator of a committee or a member of the secretariat or had a similar role.

4. I was the kibbutz secretary, economic coordinator or treasurer. 
Rotation is measured by the percent of members in a kibbutz who responded 3 or 4 to the above question. Thirty per cent of respondents checked 3 or 4 in the average kibbutz, the range extending from 2.5 per cent to 69 per cent among the 49 kibbutzim.

A third (inverse) measure of democratic and egalitarian practice is the percent of person-days of non kibbutz workers hired in industry during 1976. The hired workers are Jewish citizens of Israel and members of Histadruth (as are all kibbutz members) but unlike kibbutz members they can not participate in decision making bodies of the factory or of the kibbutz. Twenty one per cent of workers in the average factory of the 49 kibbutzim were hired from outside the kibbutz, with a range of 0 per cent to 79 per cent among the kibbutzim. (Hired workers are not respondents to any of the questionnaires of this research.)

The three aspects of democratic and egalitarian procedures do not correlate strongly with one another $(\overline{\mathrm{r}}=.25)$. We therefore treat them separately in the analysis.

D. Inequality. The coefficient of variation (standard deviation divided by the mean) and the gini ratio were used to measure inequality in each kibbutz for the distributions of several material and non material rewards or resources including self reported influence, size of the member's apartment, the esteem accorded the member by others, feeling of self actualization, commitment to the kibbutz and satisfaction with life on the kibbutz. We also attempted to create measures of status crystalization or consistency by computing alpha scores based on the intercorrelations among the measures of rewards in each kibbutz, but abandoned this measure for reasons that we shall describe below. The rationale for the coefficient of variation as a measure of inequality is discussed by Jencks (1972) and is similar to that for the simple standard deviation (Curtis and Jackson 1977) or variance (Tannenbaum and Bachman 1966). The gini ratio, which is ordinarily used to measure inequality of material wealth, has been shown by Whisler (1968) to work appropriately in measuring inequality in the distribution of influence measured subjectively on a 5 point scale. Thus, one might think of the total amount of influence or of satisfaction, esteem, commitment, or self actualization in a society as a form of its wealth, and compute through the gini ratio (or coefficient of variation) the extent to which this wealth is shared widely or held primarily by a relatively few.

Data about size of apartment are available for only 27 of the 49 kibbutzim. It was measured by asking respondents for the number of square meters of their apartment, a figure that members know well. The average apartment size is 42.2 square meters in the average kibbutz with a range among kibbutzim of from 24.0 to 54.0 square meters. In general, new apartments, which may be larger than older 
ones, are assigned members on the basis of seniority. Data available for the Artzi federation indicate no relationship between the age of a kibbutz (one of the components of the technological imperative) and its variance in the distribution of seniority. (Kibbutz Artzi Statistical Department, 1982.)

Personal influence was measured as an index based on the average of responses to two questions. One presented concentric-circles and respondents were told, 'Here are 5 concentric circles that represent your kibbutz. The central members are situated in the small one, and their score is 5 . Where do you locate yourself?' The second question asked, 'To what extent do you think that you have influence on different issues in your kibbutz?' Answers were checked on a 5 point scale from 1, 'very little influence' to 5, 'very great influence.' The alpha score of the index created by these questions is .62 .

The esteem accorded by others was measured by asking respondents, 'To what extent are you esteemed by others in the kibbutz?' Answers were checked on a 5 point scale from 1 , 'not at all' to 5, 'to a very great extent.' The term esteem is used in the questions of many studies as a measure of prestige (Treiman 1977). The present measure might therefore be taken as an indicator of personal prestige.

Self-actualization was reported by members in response to the question, 'To what extent does the kibbutz provide you opportunities to realize your aspirations for self-development?' This question was answered by checks on a 5 point scale from 1 , 'to a very little extent' to 5 , 'to a very large extent.'

The measure of member's feeling of commitment to the kibbutz was created as an index that averages the scores in response to 4 questions:

1. 'To what extent are you involved in the issues of your kibbutz?' (1, not at all ...5, to a very large extent)

2. 'If one of your friends were not sure about his membership in the kibbutz, would you try to convince him to stay in the kibbutz?' ( 1 , never ... 5, always)

3. 'If you are in a conflict situation between your own interest and the general needs of the kibbutz, how likely are you to give priority to the needs of the kibbutz?' ( 1 , never . . . 5, always)

4. 'To what extent do you feel your fate is linked to your kibbutz?' ( 1 , to a very little extent . . . 5, to a very large extent)

The alpha score of this index, based on an average of these questions is .66 .

A measure of satisfaction with kibbutz life is based on an index of responses to the following items

'To what extent are you satisfied with,

a. the possibilities you have to influence what is going on in your kibbutz?' 
b. your social position in the kibbutz?'

c. your standard of living?'

d. your occupation at work?'

e. your life in general at the kibbutz?'

Each of these questions was answered on a scale from 1, 'not satisfied at all' to 5, 'very satisfied.' The index composed of an average of these items has an alpha of .71.

The gini ratio correlates well (between .53 and .95) with the coefficient of variation for each of the above subjective variables, excepting esteem $(r=.30)$. The gini and the coefficient of variation were therefore combined to create a 'combined index of inequality' for each subjective variable, with alphas of from .70 to .98 , excepting esteem which has an alpha of only .33. The gini ratio and coefficient of variation for apartment size, however, do not correlate significantly with one another and they are therefore treated separately.

There is little consistency among kibbutzim in the way influence and the various material and non material rewards are distributed. Kibbutzim that are relatively inegalitarian on one characteristic are not predictably inegalitarian on others, the average correlation among various measures of inequality being . 15 . Inequality in the kibbutz, to the extent that it occurs, is not highly 'structured' or 'crystalized' (Adar 1982; Rosner and Shur 1980). Leviatan (1970) for example, found virtually no relationship between a member's professional status and his/her position in the community hierarchy or between a member's position in the community hierarchy and position in the work hierarchy. A worker is as likely to have a high position in the community hierarchy as is a manager of a work branch. Leviatan did, however, find a small, statistically significant relationship between professional status and position in the work hierarchy, although Tannenbaum et al. (1974) found that factory managers in kibbutz plants do not have a higher level of education than workers have. In the present study we found that level of education, which is a correlate of income and occupational status in many societies, (Curtis and Jackson 1977; Treiman 1977) relates poorly to income. Members do not receive income in the usual sense except that all receive an identical and modest monetary allowance. Members may, however, differ from one another in the material goods they receive or consume. One such good that we have measured, apartment space, might be taken as a surrogate for income. It correlates only .02 with education. Shur (1982) found a correlation in the kibbutz of only .02 between a member's level of education and self perceived consumption of material goods. He also found only very small correlations, .02 and -.01 respectively, between education and prestige (measured in terms of the esteem perceived by a member that is accorded to $\mathrm{him} /$ her by others) and between prestige and perceived consumption. 
Because the several measures of inequality do not correlate well with one another we shall treat separately as dependent variables the combined indices (gini and coefficient of variation) of each subjective variable along with the coefficient of variation and the gini for apartment size.

\section{RESULTS}

We do not find support for Hypothesis 1; the correlation between the technological and ideological imperatives is .01. None the less, a number of the correlations in Table III appear supportive of the initial hypotheses about the opposing effects of the technological and ideological imperatives. This table presents zero order correlations between the predictors in these hypotheses (vertical axis) and the variables to be predicted. All of the data from the four studies described above were standardized by study prior to computing these correlations (vide supra). We have applied the conservative, two tailed test to the calculation of significance levels even though our predictions are directional, so that we could evaluate the significance of correlations that might be in a contrary direction.

According to Table III, and consistent with the initial hypotheses, the more industrialized kibbutzim are less likely to be participative, $(\mathrm{r}=-.27)$ to practice officer rotation $(\mathrm{r}=-.40)$ and to avoid the hiring of outside labor $(r=-.20$, although this correlation is not significant statistically). The more industrialized kibbutzim are also more likely to be inegalitarian, at least with respect to influence $(r=$ $.26)$ and the distribution (measured by the coefficient of variation) of apartment space $(\mathrm{r}=.48)$. Several correlations, however, are problematic for the initial hypotheses. The education level of members stands out in this regard. We conceived of education as part of the technological imperative syndrome consistent with arguments and documentation in the literature (Russett et al. 1964; UNESCO 1958) but the education level of members as we have seen earlier does not relate well in the kibbutz to industrialization or to other components of the syndrome and we therefore did not include it in the index. Furthermore, it yields results in Table III quite contrary to our initial hypothesis that, as part of the technological imperative syndrome, it would be related positively to inequality in the kibbutz. On the contrary, education appears conducive to equality, at least with respect to members' apartment space and satisfaction with and commitment to the kibbutz.

The correlation between participation and inequality in distribution of apartment space also yields a result contrary to the hypothesis. We shall consider in our concluding section the meaning of these contradictions. 


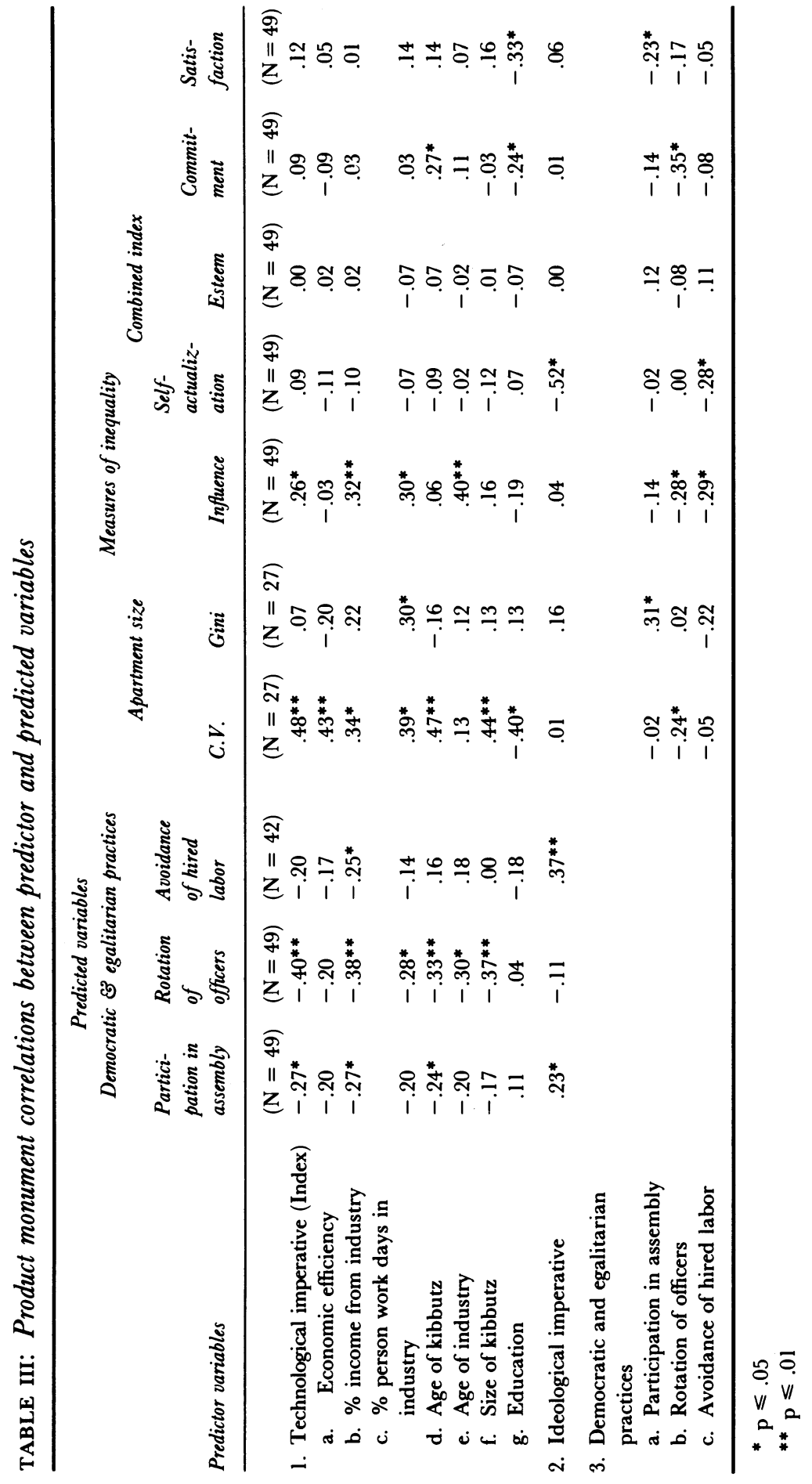


Table IV presents the regressions of stage 1, the technological and ideological imperatives, predicting democratic and egalitarian practices, stage 2 of the model in Figure I. Education is included as a separate predictor. These results, by and large are consistent with those of Table III suggesting opposing effects of the technological and ideological imperatives on democratic and egalitarian practices.

TABLE IV: Standardized regressions predicting democratic and egalitarian practices from the technological and ideological imperatives

\begin{tabular}{lccc}
\hline & \multicolumn{3}{c}{ Democratic and egalitarian practices } \\
& $\begin{array}{l}\text { Participation } \\
(N=49)\end{array}$ & $\begin{array}{l}\text { Rotation } \\
(N=49)\end{array}$ & $\begin{array}{l}\text { Avoidance of } \\
\text { hired labor } \\
(N=42)\end{array}$ \\
\hline \multicolumn{1}{c}{$\mathrm{R}^{2}$} & .14 & $.17^{*}$ & .17 \\
Predictors: & & & \\
Technological imperative & -.28 & $-.40^{* *}$ & -.20 \\
Education & .10 & .03 & .05 \\
Ideological imperative & $.23^{*}$ & .11 & $.37^{* *}$ \\
\hline${ }^{*} \mathrm{p} \leqslant .05$ & & & \\
${ }^{* *} \mathrm{p} \leqslant .01$ & & &
\end{tabular}

Table $\mathrm{V}$ presents regressions predicting the measures of inequality from stage one of Figure I. Here again, we see some indication of the predicted opposing effects of the two imperatives although the number of significant betas is small and education shows a negative association with some measures of inequality, contrary to our initial conception.

Table VI presents the regressions of stages 1 and 2 predicting inequality. The rate of statistically significant results is lower in this table than in the previous ones, perhaps because of the fewer degrees of freedom here. Otherwise, the results are consistent in their implications with those of previous tables.

\section{SUMMARY AND GONGLUSIONS}

Sociologists disagree about the extent to which the kibbutz is an egalitarian society. According to some, the kibbutz has abandoned egalitarianism and has created a special 'managerial weltanschauung' among the upper stratum. (e.g., Rayman 1981; Rosenfield 1951) Our own observations lead us to conclude that the kibbutz is relatively egalitarian compared to other modern societies. Differences among members in income and wealth are small compared to such differences elsewhere. All members live in similar cottage apartments, eat their main meals together and draw more or less equally upon the 


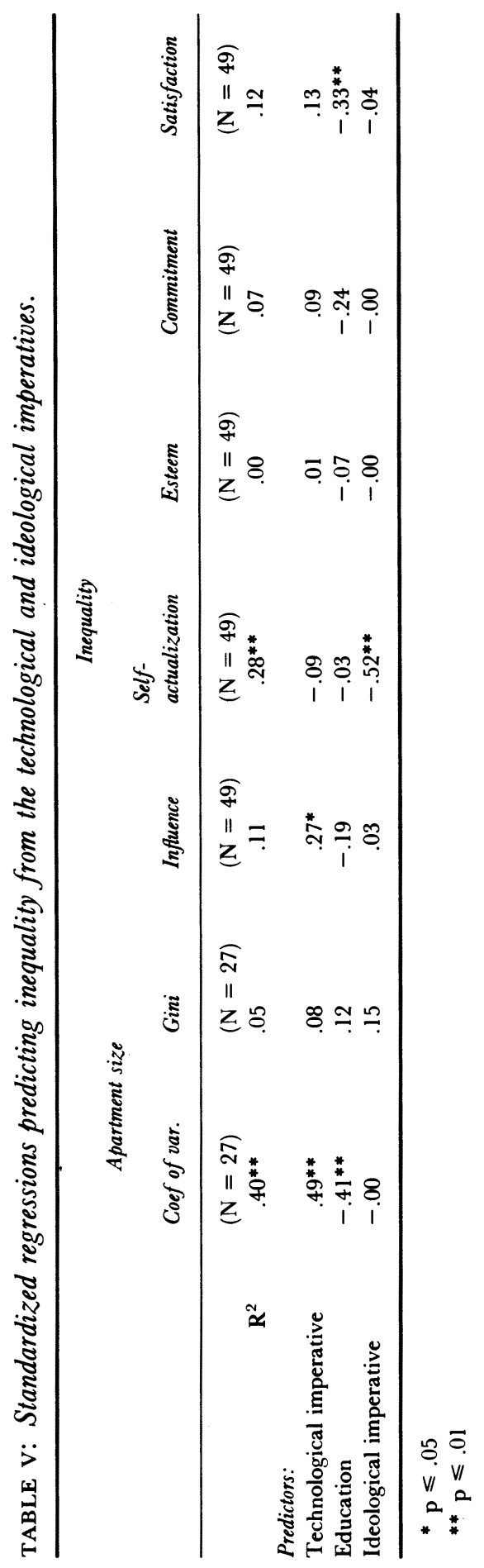




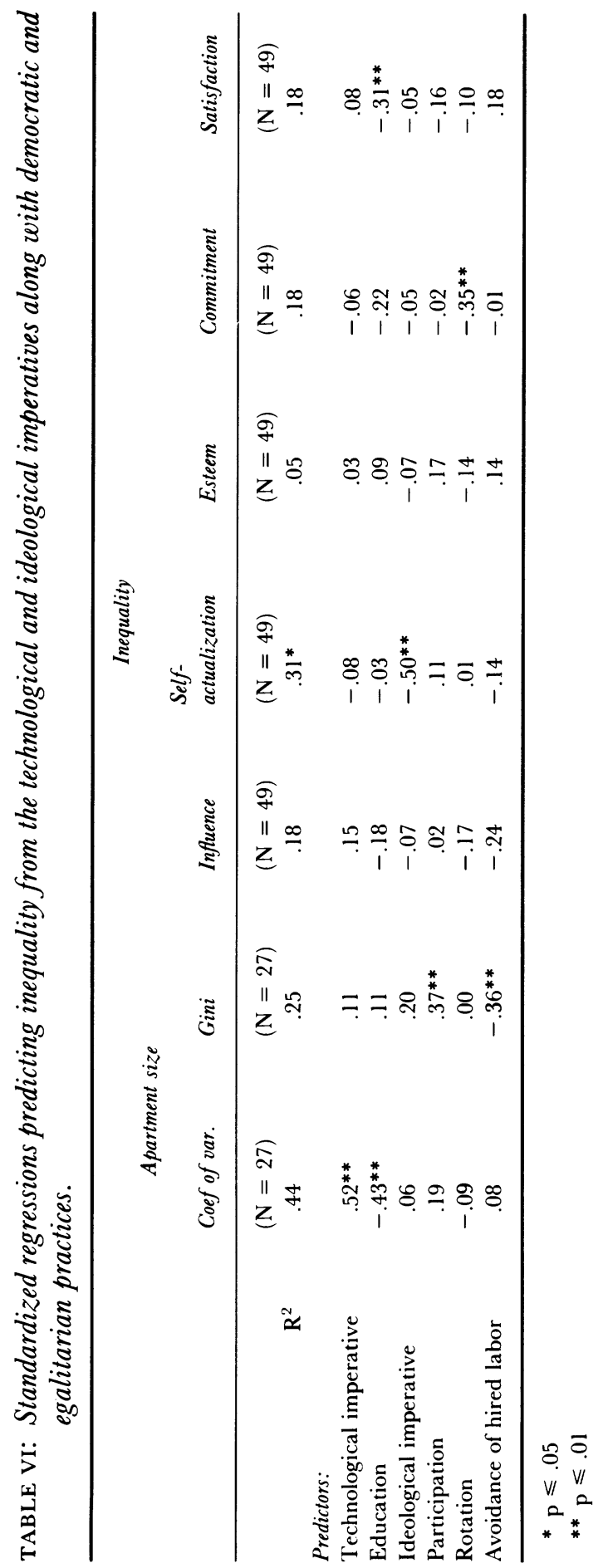


material resources of the kibbutz. None the less, kibbutzim differ from one another in the extent to which they maintain democratic and egalitarian practices and equality itself, and these differences appear to be explained in part by the opposing effects of a technological and an ideological imperative.

The technological imperative relates negatively and the ideological imperative relates positively to two of three measures of democratic and egalitarian procedures (Table IV). Kibbutzim high on the technological imperative - kibbutzim that are older, larger, more industrialized and profitable — are likely to be relatively less participative and to have a relatively low rate of turnover among officers. In addition, kibbutzim high on the ideological imperative those in the more ideologically orthodox Artzi Federation - are likely to be relatively more participative and restrained in the hiring of outside labor.

Furthermore, the technological and ideological imperatives do show the predicted association with several indices of inequality. However, while the technological imperative has a 'direct effect', to use the terminology of Alwin and Hauser (1975), on the coefficient of variation of apartment size (Table $\mathrm{VI} ; \boldsymbol{\beta}=.52$ ) there is no significant 'indirect effect' of the technological imperative through any of the measured democratic and egalitarian procedures as we had proposed. Similarly, while the ideological imperative has a predicted 'direct effect' on inequality in feeling of self actualization $(\beta=-.50)$ there is no significant 'indirect effect' through democratic and egalitarian practices. None the less, zero order correlations indicate associations between these practices and a number of the measures of inequality, consistent with our hypothesis. Kibbutzim with high rates of officer rotation are likely to be relatively egalitarian in distribution of apartment space (measured through the coefficient of variation), distribution of influence and feeling of commitment to the kibbutz. Similarly, kibbutzim that avoid the employment of outside labor are relatively egalitarian in distribution of influence and self actualization. And participative kibbutzim are relatively egalitarian in the distribution of satisfaction among members. One result, however, is distinctly contrary to that predicted. Participative kibbutzim are relatively inegalitarian in distribution of apartment space, measured through the gini ratio.

The concepts of participation and of equality are so much allied ideologically in the kibbutz that a negative empirical relationship between them appears, at first blush, contradictory. Participative decisions, however, can be inegalitarian in their consequences; a large number of persons can make decisions that advantage or disadvantage a small number of persons. Thus, the general assembly of the kibbutz may attract participants who have a cause to plead and who hope through participation to further their cause. Other members may be 
drawn to the meetings because of the implications of that cause for their own welfare. Many members may therefore be stimulated to participate because the outcomes of the decisions imply some potential advantage or disadvantage to them. And, in fact, this highly participative procedure may result in decisions that do have inegalitarian consequences. A decision to build new cottage apartments, for example, could very well result in differences among members in the space available to them. The new cottages are likely to be larger than the older ones but the kibbutz can not replace all of its old cottages simultaneously. Some members will therefore have to reside in older, smaller cottages while others will move into newer, larger ones. Hence there may be a positive relationship between participation and some aspects of inequality. On the other hand, where there is relatively high participation, members are more equally satisfied with life on the kibbutz, consistent with our initial hypothesis.

Education, which we had conceived as part of the technological imperative, also yields several correlations that run counter to our initial hypothesis. Kibbutzim in which members are relatively high in education are more egalitarian, not less, at least with respect to the distribution of apartment space (measured by the coefficient of variation) and feeling of commitment and of satisfaction. Nor is average level of education associated with industrialization in the kibbutz as it probably is in other societies (Russett et al. 1964; UNESCO 1950). Industrialization in the kibbutz, unlike industrialization in many other societies, has been taking place within a population that had already achieved a relatively high level of education. Most of the founders of the kibbutz were university students who interrupted their studies to become agricultural workers. They provided a high school education for their children but they were reluctant to send their sons and daughters to universities until the late 1960s when, along with rapid industralization, large numbers of kibbutz born persons were given higher education. (Gamson 1975) Level of formal education as a variable in the kibbutz, therefore, has a historical trajectory different from that in the typical modernizing society, and while education may be a significant component of the technological imperative elsewhere its relationship to the imperative in the kibbutz is more complex.

Cross sectional data can not provide evidence concerning causality. None the less, the data of this research offer modest evidence consistent with some of the general arguments that we cited concerning effects of the technological and ideological imperatives. The evidence, we believe, is only modest partly because inequality in the kibbutz is not highly structured or crystallized. Persons who are high on one of the 'rewards' we have measured, such as apartment space, are not necessarily high on others such as influence, or 
satisfaction. Similarly, kibbutzim that are relatively inegalitarian with regard to one of the characteristics that we have measured are not necessarily inegalitarian with regard to the others. Inequality within a kibbutz is therefore more elusive than it is in societies where inequality is highly structured, and a kibbutz cannot easily be characterized by a global measure of inequality. In addition, kibbutzim as a set are relatively homogeneous; they do not differ very much from one another, as, for example, they might differ from other societies in inequality and in the technological and ideological imperatives. It is partly because of this homogeneity and lack of crystallization, we believe, that the effects on equality that we have found are small and sporadic. The measurement of differences in inequality among societies is not likely to be highly reliable where the societies do not differ very much and consistently from one another in equality. The small number of sampled persons who provided the data used to measure inequality within each kibbutz also limits the reliability of the measures and therefore the likelihood of detecting relationships that exist. In spite of these limitations, however, we have found a number of relationships that can not be explained by chance. The technological imperative in the kibbutz, measured through an index of industrialization, economic efficiency and aspects of growth, does appear to have negative implications for some democratic and egalitarian practices and for aspects of equality itself. And these effects appear to be counteracted in some degree by education and by an ideological imperative that implies commitment to the traditional kibbutz values of democracy and equality.

The opposing effects of the two imperatives would seem to be consistent with the assertion that all societies face a 'basic Gemeinschaft-Gesellschaft value dilemma' (Blasi 1978) and with the criticism of utopian societies 'that social life cannot be both "human and efficient"' (Kanter 1972: 148). The lack of relationship between the two imperatives themselves, however, does not support this argument. We can not assert unequivocally that a relationship does not exist between the two imperatives, but the data would seem at least to suggest this as a hypothesis worth considering. If this hypothesis has validity, the practices in technologically oriented kibbutzim could conform more than they do to traditional values, given a commitment to those values.

The technological and ideological imperatives presumably have effects on egalitarian and democratic practices and on equality itself through decisions that are made and actions that are taken in the kibbutz. But each imperative implies a range of possible prescriptions for action that differ from one another in their degree of consistency with the other imperative. The variety of potential prescriptions that advance economic efficiency, for example, and that reflect the technological imperative might include some that are more and others 
that are less inconsistent with equality. While most of the potential prescriptions (especially the more obvious ones) may imply a degree of inegalitarianism, some prescriptions might be inconsequential for inequality and a rare few might even be supportive of egalitarian practice. In principle, prescriptions can therefore be chosen to maximize (or satisfice) on both imperatives. For example, the striving for technical and economic efficiency might lead to the decision to introduce an industrial plant into a kibbutz. Not all plants and their sociotechnical arrangements, however, are alike in their implications for equality and democracy. Some labor intensive industries 'call for' hired labor more than do other industries. Similarly, some industries in which many of the tasks are extremely routine and boring create a strong incentive for members to hire outside workers. On the other hand, 'knowledge-intensive' industries include a large proportion of jobs that require substantial training, are relatively high in occupational prestige and provide workers opportunities to learn as they work and to exercise some influence in the work place. Such industries are, relatively speaking, consistent with kibbutz ideology. (Leviatan 1980) Similarly, some technologies more than others lend themselves to organic organization and to the use of autonomous work groups that are consistent with participative and egalitarian principles more than is typically the case in industry. Techniques of job enrichment, job rotation, and even training to enhance skills in participative leadership might also be incorporated in some plants more easily than in others as means of mitigating if not eliminating the inegalitarian effects of the industrial hierarchy - without sacrificing technological efficiency.

Where the ideological imperative is strong, prescriptions that satisfy the technological imperative will presumably be selected from among alternatives that are the least inegalitarian, including perhaps even some that do not undermine equality at all - providing that the decision makers are able to formulate a broad range of potential prescriptions (including some less obvious ones that are reasonably benign ideologically) and providing that the decision makers are able to understand and therefore anticipate the consequences of the prescriptions for equality. This crucial intellectual capacity, however, has been and is limited in the kibbutz (as elsewhere) and the rationality of decisions concerning these issues is therefore highly 'bounded.' Thus, historically, the prescriptions designed to enhance technical efficiency, having been selected from the obvious set that includes predominantly inegalitarian formulations, and having been chosen partly in ignorance of consequences has led to a drift toward inequality. The drift may be continuing, although perhaps not inevitably. If a commitment to traditional values can coexist with the striving for efficiency, the problem is one of enhancing the capacity of the kibbutz to understand and to formulate prescriptions that further the objectives of each 
imperative and that are relatively benign with respect to the other. The fact that the education level of members is associated with equality in the kibbutz, contrary to our initial conception, may be a clue indicative of the effect of such understanding.

Kibbutz members have recognized the need for greater sophistication in their effort to reconcile the striving for technical efficiency and the maintaining of practices consistent with traditional values. They have turned in part to social science to help solve this and related problems that the kibbutz faces as it grows and modernizes. (Leviatan and Rosner 1980) If the effort should prove successful, this fact itself will illustrate how technical rationality might contribute to the realization of 'human ideals' like democracy and equality in a communal society.

\author{
Menachiem Rosner \\ Haifa University \\ and \\ Arnold S. Tannenbaum \\ University of Michigan
}

\title{
Notes
}

1. Both authors contributed equally to this article. We are deeply grateful to Yacov Gluck for his help in the data analysis and to Ephriam Yuchtman Yaar for his helpful comments to an earlier draft. This study was supported by the National Science Foundation, grant no.
SES - 8112280.

2. At the time of the data collection for this study, the kibbutzim were formed into the federations, Artzi, Meuchad, Ichud, and Dati. More recently, two of the federations, Meuchad and Ichud have merged.

\section{BIBLIOGRAPHY}

Adar, G. 1982. 'Occupational prestige in the kibbutz,' Interchange 13, 1:45-54.

$\rightarrow$ Alwin, D. F. and Hauser, R. M. 1975. 'The decomposition of effects in path analysis,' American Sociological Review 40: 37-47.

Blasi, J. 1978. Assessing the Quality of Life in Small Communities. Cambridge, Mass.: Institute for Cooperative Community.

Buber, M. 1958. Paths in Utopia, Boston: Beacon Press.

Cohen, E. 1966. 'Progress and communality-value dilemmas in the collective movement,' Internat.' Rev. Com. Dev. 15 (16):3-8.

Cooley, C. H. 1962. Social Organization: $A$ Study of the Larger Mind. New York:
Schocken Books.

Curtis, R. F. and Jackson, E. F. 1977. Inequality in American Communities. New York: Academic Press.

Dahrendorf, R. 1970. 'On the origin of inequality among men' in Laumann, Siegal, and Hodge, The Logic of Social Hierarchies. Chicago: Markham Publishing.

Erasmus, C. J. 1977. In Search of the Common Good: Utopian Experiments Past and Future. New York: The Free Press.

Gamson, Z. 1975. 'The kibbutz and higher education: Cultures in collision', Jewish Sociol. and Soc. Res. 2(1):10-28.

Gouldner, A. W. 1976. The Dialectic of Ideology and Technology. New York: The 
Seabure Press.

$\rightarrow$ Hewitt, C. 1977. 'The effect of political democracy and social democracy on equality in industrial societies: A crossnational comparison'. A. Sociol. Rev. 42: 450-64.

Jencks, C. 1972. Inequality. New York: Harper and Row Publishers.

Kanter, R. M. 1972. Commitment and Community: Communes and Utopias in Sociological Perspective. Cambridge, Mass.: Harvard University Press.

Katz, D. and Golomb, N. 1974. 'Integration effectiveness and adaptation in social systems: A comparative analysis of kibbutzim communities,' Admin. and Society 6(3):283-315.

Katz, D. and Golomb, N. 1975. 'Integration effectiveness and adaptation in social systems: A comparative analysis of kibbutzim communities,' Admin and Society 6(4):389-421.

Kibbutz Artzi Statistical Department Demographic Data about the Kibbutz Artzi for this year 1981. 1982. Tel Aviv: Kibbutz Artzi Statistical Department (Hebrew).

Kressel, G. 1974. From Each According to His Ability . . , Stratification vs. Equality in a Kibbutz. Tel Aviv: Cherikover B. Publishers (Hebrew).

Leviatan, U. 1970. 'Status in Human Organizations as a Determinant of Mental Health and Performance'. Unpublished doctoral dissertation Ann Arbor, Michigan: University of Michigan.

Leviatan, U. 1980. 'Importance of knowledge - intensive occupations for the kibbutz society,' in Leviatan and Rosner, Work and Organization in Kibbutz Industry Darby, PA: Norwood Editions.

Leviatan, U., Amad, Z. and Adar, G. 1982. Aging in the Kibbutz: Satisfaction With Life and With Its Antecedents. Haifa, Haifa University: The Institute for Kibbutz Studies Publications.

Leviatan, U., Orchan, E. and Avnat, A. 1977. Increasing Retention Among Kibbutz-born Members. Haifa, Haifa University The Institute for Kibbutz Studies Publications.

Leviatan, U. and Rosner, M. 1980 (eds), Work and Organization in Kibbutz Industry. Darby, PA: Norwood Editions. Likert, R. 1961. New Patterns of Manage- ment. New York: McGraw-Hill.

Manuel, F. E. and Manuel, F. P. 1972. Utopian Thought in the Western World. Cambridge, MA: Harvard University Press.

Marx, K. 1934. The Poverty of Philosophy. Chicago: Charles Kerr and Co.

Mayo, E. 1954. The Social Problems of an Industrial Civilization. Boston: Harvard Business School.

McGregor, D. The Human Side of Enterprise. New York: McGraw-Hill.

Rabin, A. and Hazan, Y. (eds). 1973. Collective Education in the Kibbutz: From Infancy to Maturity. New York: Springer.

Rayman, P. 1981. The Kibbutz Community and Nation Building. Princeton, N.J.: Princeton University Press.

Rosner, M. and Cohen, N. 1982. 'Is direct democracy feasible in modern society? The lesson of the Kibbutz experience,' in Rosner (ed.), Democracy, Equality, and Change: The Kibbutz and Social Theory. Darby, PA.: Norwood Editions.

Rosner, M., Gluck, Y. and Avnat, A. 1982. 'Satisfaction with consumption as affected by economic social and value factors,' in Rosner (ed.), Democracy, Equality, and Change: The Kibbutz and Social Theory. Darby, PA: Norwood Editions.

Rosner, M., David, I.B., Avnat, A., Cohen, N. and Leviatan, U. 1978. The Second Generation. Tel Aviv: Sifriat Hapoalim (Hebrew).

Rosner, M. and Shur, S. 1980. Structural Equality in the Kibbutz. Haifa, Haifa University: The Institute for Studies of the Kibbutz Publications.

Rousseau, J. J. The Social Contract (1972). New York: Dutton.

Russett, B. M., Alker, Jr., M. R., Deutsch, K. W. and Lasswell, H. D. 1964. World Handbook of Political and Social Indicators. New Haven, CT: Yale University Press.

Schoeck, H. 1971. Der Neid und die Gesellschaft. Freiburg: Herder.

Shashua, L. and Goldshmidt, G. 1974. 'An Index for Evaluating Financial Performance,' J. Finance 39:797-817.

Shur, S. 1982. The Problem of Equality in the Kibbutz Movement. Haifa, Haifa University: The Institute for Studies of the Kibbutz Publications (Hebrew). 
Skinner, B. F. 1948. Walden Two. New York: Macmillan.

Skinner, B. F. 1971. Beyond Freedom and Dignity. New York: Knopf.

Talmon-Garber, Y. G. 1972. Family and Community in the Kibbutz. Cambridge, MA: Harvard University Press.

Tannenbaum, A. S. and Bachman, J. 1966. 'Attitude uniformity and role in :voluntary organization,' Hum. Rel. 19(3): 309-22.

Tannenbaum, A. S., Kavćić, B., Rosner, M., Weiser, G. and Vianello, $M$. 1974. Hierarchy in Organizations. San Francisco, CA: Jossey Bass Inc.

Tiger, L. and Shepher, J. 1975. Women in the Kibbutz. New York: Harcourt, Brace, Jovanovich.

Tonnies, F. 1955. Community and Association. London: Routledge \& Kegan Paul, Ltd.

Treiman, D. J. 1974. 'Industrialization and Social Stratification,' Sociological Inquiry 40 Spring, pp. 207-34.

Treiman, D. J. 1977. Occupational Prestige in Comparative Perspective. New York: Academic press.

UNESCO. 1958. World Survey of Education. Vol II, Primary Education. New York: United Nations.

Vallier, I. 1962. 'Structural Differentiation, Production Imperatives and Communal Norms,' Social Forces 40:233-42.

Weber, M. 1947. The Theory of Social and Economic Organization. Oxford: Oxford University Press.

Wilson, B. R. 1973. Magic and the Millennium. New York: Harper and Row.

Whisler, T. L., Meyer, H., Baum, B. H. and Sorensen, P. F. 1968. 'Centralization of organizational control: An empirical study of its meaning and measurement,' in Tannenbaum, A. S. (ed.) Control in Organizations New York: McGraw-Hill.

\section{APPENDIX A}

Formula for the Computation of the Economic Success Score of a Kibbutz (Shashua and Goldshmidt, 1974)

$\overline{\mathrm{Y}}=15+0.41 \mathrm{x}_{1}+0.83 \mathrm{x}_{2}+0.15 \mathrm{x}_{3}+0.11 \mathrm{x}_{4}-0.15 \mathrm{x}_{5}+0.2 \mathrm{x}_{6}$

where, $\bar{Y}=$ Economic success

$\mathrm{x}_{1}=\frac{\text { Income }- \text { Expenditure }}{\text { Income }}$

$\mathrm{x}_{2}=\frac{\text { Income }-(\text { Expenditure }+ \text { Paid Interest }+ \text { Depreciation })}{\text { Income }}$

$\mathrm{x}_{3}=$ Net profit (after taxation) $+\frac{\text { Amount spent on Consumption }}{\text { No. of Families }}$

(Weighted to the 1968 cost of living index and rounded to 100 lira)

$\mathrm{x}_{4}=\%$ of accumulated capital out of total fixed assets

$\mathbf{x}_{5}=$ 'Liquidity Gap' as \% of production (How much of the fixed assets are financed with short term loans)

$\mathrm{x}_{6}=\%$ of production that is obtained from borrowed money on which interest is paid 